\title{
Kontekstualisme Elemen Fasad Hotel Ibis Styles Braga Terhadap Fasad Bangunan Eks Bank Denis
}

\author{
Reza Phalevi Sihombing ${ }^{1}$, Riska Yuliana Desilia ${ }^{1}$, Sarah Nurhasanah 1, \\ Fikri Aulia Rachman ${ }^{1}$ \\ ${ }^{1}$ Program Studi Arsitektur, Fakultas Arsitektur dan Desain \\ Itenas, Institut Teknologi Nasional Bandung \\ Email: rezaphalevis@itenas.ac.id
}

\begin{abstract}
ABSTRAK
Indonesia memiliki banyak kawasan bersejarah, salah satunya berda di dalam kawasan Jalan Braga Kota Bandung. Kehadiran bangunan baru di kawasan ini menjadi perhatian khusus bagaimana desain olahan fasad yang akan diterapkan pada fasad bangunannya. Pada studi ini akan membahas bagaimana usaha bangunan baru dalam mendesain fasad bangunan sehingga dapat mengaitkan diri dengan fasad bangunan di lingkungan sekitarnya. Dengan menggunakan metoda deskriptif kualitatif dan metoda kuantitatif, penelitian ini akan meninjau desain elemen fasad Hotel Ibis Styles Braga terhadap bangunan eks Bank Denis yang merupakan bangunan cagar budaya. Karena bangunan cagar budaya dapat dijadikan tolak ukur desain untuk bangunan. Studi literatur digunakan untuk membandingkan antara teori arsitektur kontekstual, dengan teori elemen fasad. Selain dari studi teori yang ada, dilakukan juga pengamatan langsung kawasan dan bangunan sekitarnya. Khususnya pada bagian fasad dan tipologi bangunan kolonial. Hasil studi secara kualitatif memperlihatkan adanya keterkaitan elemen fasad pada bangunan Hotel Ibis Styles Braga terhadap bangunan Eks Bank Denis, namun secara kuantitatif terdapat perbedaan ukuran proporsi terhadap bentuk dari elemen fasad tersebut. Dari pengamatan arsitektur kontekstual yang dilihat dari segi fasade bangunan. Pada fasad bangunan Hotel Ibis Styles Braga memiliki pendekatan konsep selaras dengan fasad bangunan eks bank denis.
\end{abstract}

Kata kunci: Cagar Budaya, Bersejarah, Kontekstual, Fasad.

\begin{abstract}
Indonesia has many historical areas, one of which is located in the area of Jalan Braga, Bandung City. The presence of new buildings in this area is of particular concern to how the processed facade designs will be applied to the building facades. This study will discuss how new building businesses are in designing building facades so that they can relate to the facades of buildings in the surrounding environment. By using qualitative descriptive and quantitative methods, this study will review the design elements of the facade of the Hotel Ibis Styles Braga to the former Denis Bank building which is a cultural heritage building. Because cultural heritage buildings can be used as design benchmarks for buildings. Literature studies are used to compare the contextual architectural theory with the facade element theory. Apart from existing theoretical studies, direct observations of the area and surrounding buildings were also carried out. Especially in the facade and typology of colonial buildings. The results of the qualitative study show that there is a relationship between the facade elements of the Ibis Styles Braga Hotel building to the former Denis Bank building, but quantitatively there are differences in the size proportions of the shape of the facade elements. From the contextual architectural observations seen in terms of the building facade. The building facade of the Hotel Ibis Styles Braga has a conceptual approach in line with the facade of the former denis bank building.
\end{abstract}

Keywords: Heritages, Historical, Contextual, Facade. 
Reza, dkk.

\section{PENDAHULUAN}

Banyak peninggalan bangunan bersejarah yang memiliki nilai seni budaya di Kota Bandung, salah satunya berada di kawasan jalan Braga. Sejak jaman pemerintahan Hindia-Belanda kawasan ini cukup dikenal sebagai jalan kecil di depan pemukiman yang tidak terlalu ramai dan berkembang pesat di tahun 1900. Banyak yg menjuluki jalan Braga dengan julukan "De meest Europeesche winkelstraat van Indie" dengan arti area pertokoan Eropa yang paling terkenal di Hindia, hal tersebut karena toko-toko yang berada di jalan Braga mengikuti gaya arsitektur Eropa (Haryoto Kunto 1984)[1].

Saat ini mayoritas bangunannya digolongkan kedalam bangunan cagar budaya. Diantara bangunan cagar budaya tersebut terdapat bangunan yang sudah tidak dipergunakan lagi, sehingga keadaanya tidak terawat. Oleh karena itu pemerintah berusaha untuk menghidupkan kembali kawasan tersebut dengan cara menawarkannya kepada investor yang mau mengelola dan tetap melestarikan bangunan tersebut. Salah satu bangunan cagar budaya tersebut ialah bangunan hotel yang sekarang menjadi Hotel Ibis Styles Braga Bandung. Pada bagian depan bangunan Hotel Ibis Styles Braga merupakan bangunan eks Hotel Wilhelmina, yang dikategorikan sebagai bangunan cagar budaya kelas B yang tetap dipertahankan kondisi bangunan awalnya sesuai dengan peraturan pelestarian bangunan cagar budaya kelas B.

Sedangkan pada bagian belakang Hotel Ibis Styles Braga merupakan bangunan baru hasil dari pemugaran yang dilakukan dengan cara revitalisasi, yang menjadi permasalahan desain terkait bagaimana usaha bangunan baru mengaitkan diri dengan bangunan lama-nya. Sesuai dengan kaidah arsitektur kontekstual, keterkaitan desain fasad antara bangunan baru dengan bangunan lama Hotel Ibis Styles Braga yang perlu diperhatikan ialah kaitan antara desain fasad Hotel Ibis Styles Braga baru terhadap lingkungan sekitarnya.

Eks Bank Denis merupakan bangunan yang berada di sekitar Hotel Ibis Styles Braga yang termasuk kedalam bangunan cagar budaya golongan kelas A. Bangunan cagar budaya kelas A pada umumnya merupakan bangunan yang masih terjaga keasliannya, oleh karena itu pada pembahasan ini akan menganalisa bagaimana kontekstual desain fasad Hotel Ibis Styles Braga terhadap fasad bangunan Eks Bank Denis Bandung. Karena elemen fasad pada bangunan lama atau bangunan cagar budaya merupakan objek tolak ukur bagi bangunan baru untuk mengelola fasad pada bangunanya apabila diinginkan terciptanya suatu kontinuitas visual pada kawasan tersebut.

\subsection{Bangunan Cagar Budaya Pengertian}

Bangunan Cagar Budaya merupakan susunan binaan yang dibuat dari benda buatan manusia atau benda alam untuk memenuhi kebutuhan ruangan berdinding dan/atau tidak berdinding, dan beratap". Area cagar budaya merupakan area atau kelompok bangunan yang mempunyai nilai budaya, sejarah dan nilai lainnya yang dianggap penting untuk dilestarikan dan dilindungi untuk kepentingan dokumentasi, penelitian, pendidikan, dan pariwisata[2].

\subsection{Kontekstual}

\section{Ciri- ciri Arsitektur kontekstual}

Berikut ini adalaha ciri - ciri dari kontekstual dalam arsitektur:

a. Terdapat perulangan motif/ alur dari desain bangunan sekitarnya.

b. Pendekatan dari segi ornament, gaesture, pattern, dan lain - lain terhadap bangunan yang telah berdiri awalnya diutamakan memiliki nilai histori agar mempertahankan identitas suatu tempat.

c. Menatar mutu bangunan yang telah berdiri awalnya[3]

Menurut Brent C Brolin dalam buku Architecture in Context. "Membahas bagaimana sebuah bangunan baru harus berperilaku beradaptasi dengan lingkungan sekitarnya (kontekstual). Dalam hal ini penulis mendapatkan pemahaman tentang makna kontekstual dan apa saja ciri-ciri bangunan kontekstual[4].

Terdapat tujuh poin penting untuk desain responsif, dalam buku Responsive Architecture: (1) Permeabilitas, kelancaran jalan masuk dan peredaran; (2) Variasi, memiliki perbedaan funsi dalam satu 
ruang atau zona. (3) Legibilitas, adalah wujud yang tidak sulit diketahui dan arah yang mudah diketahui; (4) kekokohan, terdapat ruang sementara, bisa digunakan agar macam-macam kegiatan yang tidak sama dalam masa yang tidak sama; (5) Kekayaan, keragaman kesan dan impresi melewati ketidak samaan materi, pengaturan ruang, dan lainnya; (6) Kesesuaian tampilan, dapat mengenali guna suatu gedung melewati wujud rupanya, tampilan kampus seperti kampus, kantor seperti kantor, hotel seperti hotel; (7) Personalisasi, mengikutsertakan masyarakat dan hubungan orang dengan sekitarnya[5].

Arsitektur kontekstual sering dikaitkan dengan kesadaran penghuni terhadap area sekitar dan kebudayaan lingkup huni[6]. Keterikatan dengan lingkup natural, sosial dan kebudayaan local adalah hal pokok untuk menekan orang agar tahu ikut sebagian dari lingkungannya. Unsur pokok budaya setempat yang berparadigma kelestarian daerah sekitar yaitu: indeks berperilaku dan bergerak melalui daerah sekitar diikuti lewat rasa percaya diri[6].

\section{Komposisi pada Fasad Bangunan}

Komponen Visual yang menjadi objek transformasi dan modifikasi fasad bangunan dapat diamati dengan melakukan klasifikasi melalui prinsip ide formatif yang menekankan pada geometri, simetri, kontras, ritme, proporsi, dan skala[7].

1. Geometri pada Fasad

2. Simetri, yaitu gagasan formatif yang mengarahkan desain bangunan melalui keseimbangan yang terjadi dalam bentuk lingkungan binaan[7].

3. Kontras adalah ide formatif yang mempertimbangkan warna dan pencahayaan

4. Irama adalah tipologi deskripsi yang memperlihatkan komponen-komponen bangunan berupa pengulangan, baik dalam skala besar maupun kecil.

5. Proporsi adalah perbandingan antara satu bagian dengan bagian lainnya dalam salah satu elemen Fasad[8].

6. Skala dalam arsitektur menunjukkan perbandingan antara unsur-unsur suatu bangunan atau ruang dengan unsur tertentu dengan ukurannya bagi manusia. Dalam konteks fasad bangunan, skala adalah proporsi yang digunakan untuk menentukan ukuran dan dimensi elemen fasad[8].

\section{Elemen Fasad Bangunan}

Menurut Krier dalam buku yang berjudul Komposisi Arsitektur, elemen fasad terdiri dari gerbang dan pintu masuk, gang beratap (arcade), lantai dasar, jendela balkon dan loggia, pagar pembatas atau railing, atap dan tingkat loteng.

1. Gerbang dan pintu masuk

Saat memasuki sebuah gedung dari arah yang salah, seseorang akan melewati berbagai gradasi yang disebut publik. Posisi pintu masuk dan signifikansi arsitekturalnya menunjukkan peran dan fungsi bangunan. Pintu masuk merupakan tanda peralihan dari publik (eksterior) ke privat (interior)[9]. Pintu masuk merupakan salah satu elemen ekspresi diri dari penghuni[9] gedung.

2. Gang beratap (Arcade)

Arkade merupakan elemen perkotaan kolektif. Arkade dapat memenuhi fungsi-fungsi semipublik dengan sengaja diletakkan di depan sebuah bangunan di mana pemakainya tidak berada di luar ataupun di dalam bangunan tersebut[10].

3. Lantai Dasar

Lantai alas/ dasar dari sebuah bangunan, adalah elemen terpenting dari sebuah fasad. Karena perpindahan langsungnya dengan tanah, maka lantai dasar terkena tekanan yang mungkin terjadi, oleh karena itu bahan yang digunakan untuk zona ini diharuskan tahan lebih lama dibandingkan dengan zona lainnya[10].

4. Jendela, balkon, dan loggia

Peran balkon, jendela dan loggia juga mewakili suatu pengayaan ruang dalam yang terbentang di belakangnya karena keduanya membagi ruang dalam ini menjadi ruang-ruang dengan nilai yang berlainan[10].

5. Pagar pembatas 
Sebuah pagar pembatas (railing) dibutuhkan ketika adanya bahaya dalam penggunaan ruang. Pagar pembatas juga menjadi pembatas fisik yang digunakan jika ada kesepakatan sosial terkait pemanfaatan ruang[9].

6. Atap dan tingkat loteng

Jenis atap ada 2 jenis yaitu jenis atap horizontal dan jenis atap yang lebih banyak ditemukan yaitu jenis alpen. Atapnya adalah bagian atas bangunan. Ujung atap dalam konteks fasad di sini dilihat sebagai batas bangunan dengan langit. Garis langit yang dibentuk oleh deretan fasad dan sosok bangunan, tidak hanya dapat dilihat sebagai pembatas, tetapi sebagai objek yang menyimpan rahasia dan ingatan kolektif penghuninya[10].

\section{METODOLOGI}

Metodologi penelitian yang digunakan adalah metodologi dengan cara melakukan identifikasi objek yang akan diteliti, kemudian mengumpulkan data terkait kasus yang akan diteliti. Hasil data merupakan data survei lapangan yang diolah secara digital dan didokumentasikan ulang. Dari data yang telah diolah kemudian dilakukan analisis mengunakan dua metode, yaitu metode analisis kualitatif dan kuantitatif. Metode kulitatif dengan cara membandingkan kedua objek kasus dengan meninjau aspek kontekstual dan fasade sesuai kajian teori yang ada, yaitu menggabungkan dan membandingkan antara teori arsitektur kontekstual dan teori elemen fasad. Sedangkan metode kuantitatif dengan cara membandingkan secara proposi kesamaan dan perbedaan kedua objek yang diteliti.

\section{HASIL DAN PEMBAHASAN}

\subsection{Elemen Fasad Gerbang dan Pintu Masuk Analisis Kualitatif Gerbang dan Pintu Masuk}

Tabel 1. Analisis Kualitatif Perbandingan Elemen Fasad Gerbang dan Pintu Masuk Bangunan Hotel Ibis Styles Braga Terhadap Bangunan Eks Bank Denis

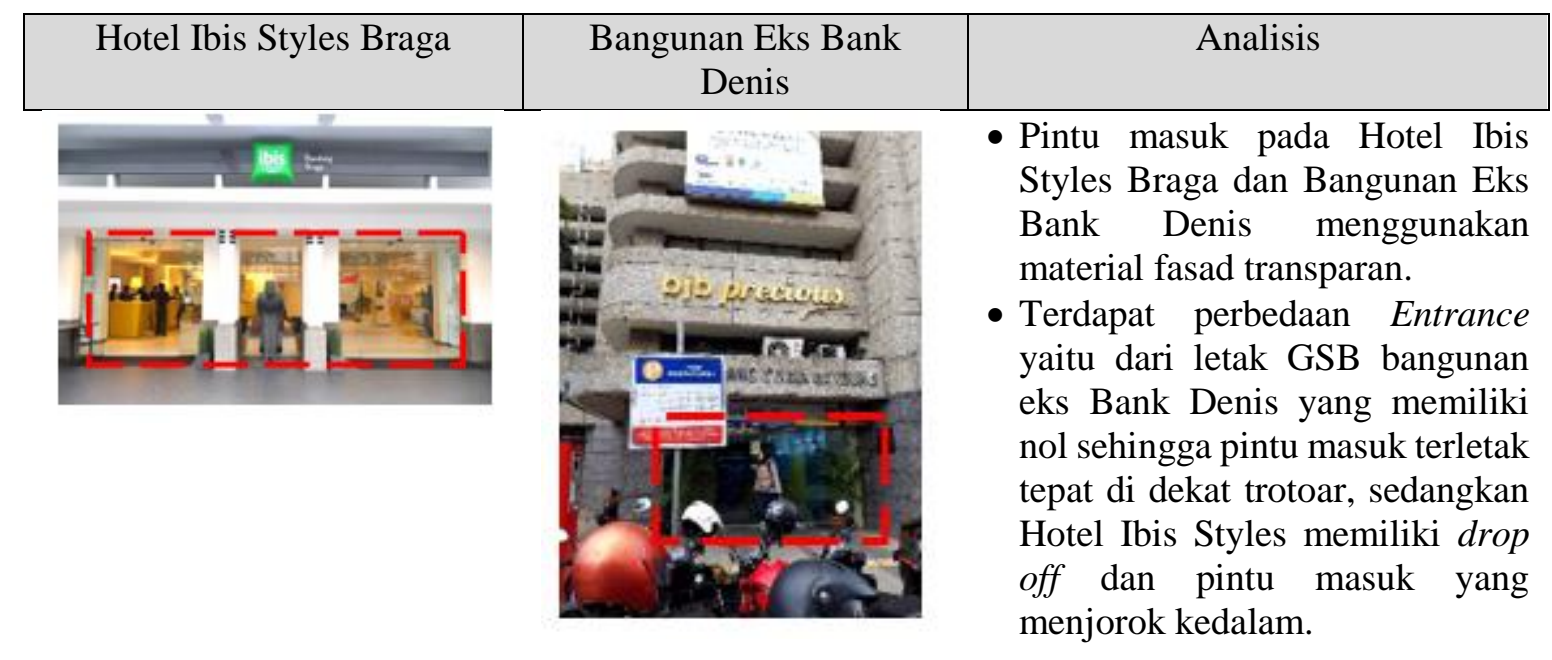

Sumber : Hasil Survei, 2019 


\section{Analisis Kuantitatif Gerbang dan Pintu Masuk}

Tabel 2. Analisis Kuantitatif Perbandingan Elemen Fasad Gerbang dan Pintu Masuk Bangunan Hotel Ibis Styles Braga Terhadap Bangunan Eks Bank Denis

\begin{tabular}{|c|c|l|l|}
\hline Hotel Ibis Styles Braga & Bangunan Eks Bank Denis & \multicolumn{1}{c|}{ Analisis } \\
\hline
\end{tabular}

Sumber : Hasil Survei, 2019

\subsection{Elemen Fasad Lantai Dasar Analisis Kualitatif Lantai Dasar}

Tabel 3. Analisa Kualitatif Perbandingan Elemen Lantai dasar Bangunan Hotel Ibis Styles Braga Terhadap Bangunan Eks Bank Denis

\begin{tabular}{|l|l|l|}
\hline Hotel Ibis Styles Braga & Bangunan Eks Bank Denis & \multicolumn{1}{c|}{ Analisis } \\
$\bullet$ & $\begin{array}{l}\text { Lantai dasar bangunan Hotel } \\
\text { lbis Styles Braga merupakan } \\
\text { bangunan lama yang memiliki } \\
\text { fasad entrance transparan dan } \\
\text { memiliki desain modern }\end{array}$ \\
seperti gambar 1, sedangkan \\
fasad lainnya memiliki desain \\
masif seperti gambar 2.
\end{tabular}

Sumber : Hasil Survei, 2019

\section{Analisis Kuantitatif Lantai Dasar}

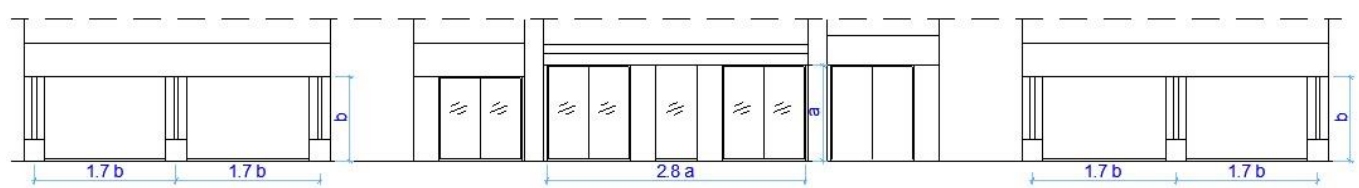

Gambar 1. Fasad Lantai Dasar Hotel Ibis Styles Braga Sumber : Hasil Survei, 2019 


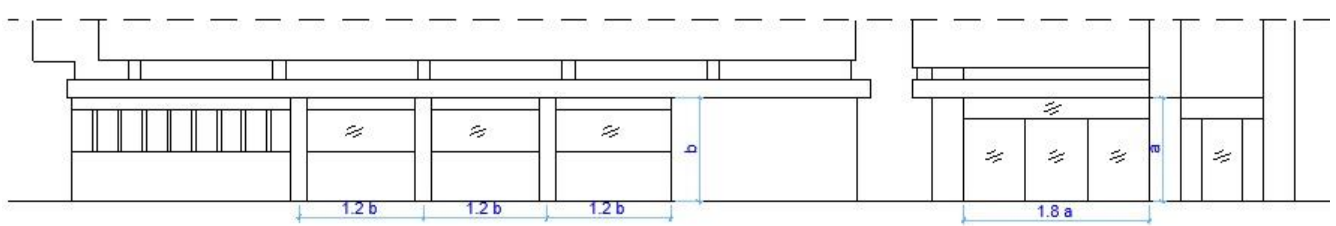

Gambar 2. Fasad Lantai Dasar Eks Bank Denis

Sumber : Hasil Survei, 2019

Analisis kuantitatif elemen fasad lantai dasar Hotel Ibis Styles Braga terhadap bangunan eks Bank Denis dengan cara memperkirakan proporsi bangunan. Terdapat perbedaan proporsi entrance bangunan yaitu Hotel Ibiss Styles Braga memiliki perbandingan a : 28 a seperti pada gambar 1 sedangkan bangunan eks Bank Denis memiliki perbandingan a : 18a seperti pada gambar 2 .

Fasad lantai dasar lainnya dilihat dari modul kolom, pada gambar 1, lantai dasar Hotel Ibis Styles Braga memiliki perbandingan b : 17b, dan pada gambar 2, lantai dasar bangunan eks Bank Denis memiliki perbandingan b : 12 b. Sehingga secara kuantitatif, Hotel Ibis Styles Braga tidak memiliki kesamaan pada elemen fasad lantai dasar dengan bangunan eks Bank Denis.

\section{3 Jendela, Balkon, dan Logia}

1. Analisa Kualitatif Jendela, Balkon, dan Logia

Tabel 4. Analisa Kualitatif Perbandingan Elemen Fasad Jendela Balkon dan Logia Hotel Ibis Styles Braga Terhadap Bangunan Eks Bank Denis

\begin{tabular}{|c|c|c|}
\hline Hotel Ibis Styles Braga & Bangunan Eks Bank Denis & Analisis \\
\hline 望 & $r$ & $\begin{array}{l}\text { Jendela pada nomor A merupakan } \\
\text { jendela yang terdapat pada tower tipikal } \\
\text { Bangunan Hotel Ibis Styles Braga. } \\
\text { Jendela pada nomor A berbentuk persegi } \\
\text { panjang disusun secara vertikal seolah- } \\
\text { olah membagi dua bidang fasad yang } \\
\text { ada di sebelahnya. Bila dilihat secara } \\
\text { konteks jendela no A1 pada bangunan } \\
\text { Hotel Ibis Styles Braga mengambil } \\
\text { motif-motif desain setempat yaitu } \\
\text { penerapan pola atau irama bukaan pada } \\
\text { bangunan eks Bank Denis yang ditandai } \\
\text { oleh no.B1 }\end{array}$ \\
\hline 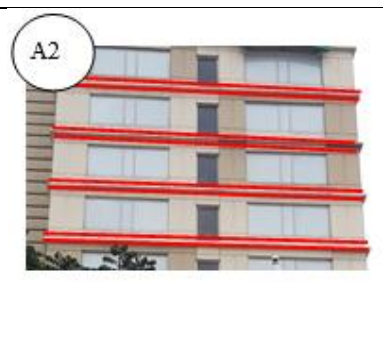 & 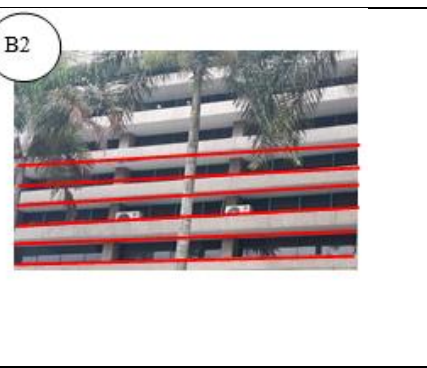 & $\begin{array}{l}\text { No. A2 pada gambar merupakan } \\
\text { keseluruhan jendela tower pada bagian } \\
\text { depan fasad bangunan Hotel Ibis Styles } \\
\text { Braga, dan No. B2 pada gambar } \\
\text { merupakan desain fasad pada bangunan } \\
\text { eks Bank Denis. Terdapat pola garis } \\
\text { horizontal pada kedua fasad bangunan } \\
\text { tersebut. }\end{array}$ \\
\hline
\end{tabular}




\section{Analisa Kuantitatif Jendela, Balkon, dan Logia}

Tabel 5. Analisis Kuantitatif Perbandingan Elemen Fasad Jendela Balkon dan Logia Hotel Ibis Styles Braga Terhadap Bangunan Eks Bank Denis

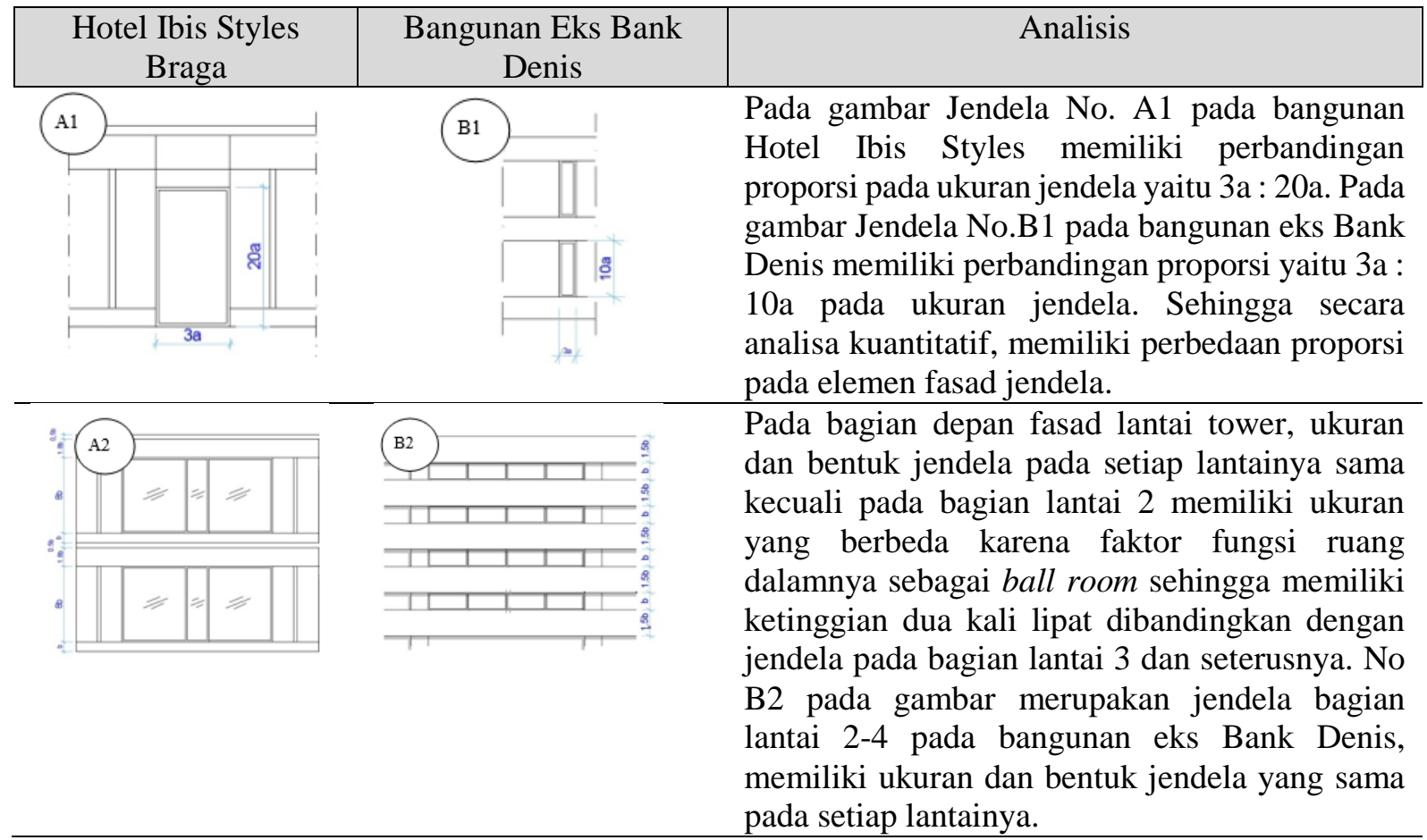

\subsection{Pagar Pembatas Analisis Kualitatif Pagar Pembatas}

Tabel 4. Analisis Kualitatif Perbandingan Elemen Fasad Pagar Pembatas Bangunan Hotel Ibis Styles Braga Terhadap Bangunan Eks Bank Denis

\begin{tabular}{lll}
\hline Hotel Ibis Styles Braga & Bangunan Eks Bank Denis & Analisis \\
\hline & $\begin{array}{l}\text { Terdapat pagar pembatas } \\
\text { pada Hotel Ibis Styles Braga } \\
\text { yang dibuat semirip mungkin } \\
\text { dengan fasad lantai 1 dan } 2 \\
\text { bangunan sehingga terlihat } \\
\text { seperti terdapat bangunan di } \\
\text { dalamnya (Gambar 1). }\end{array}$
\end{tabular}




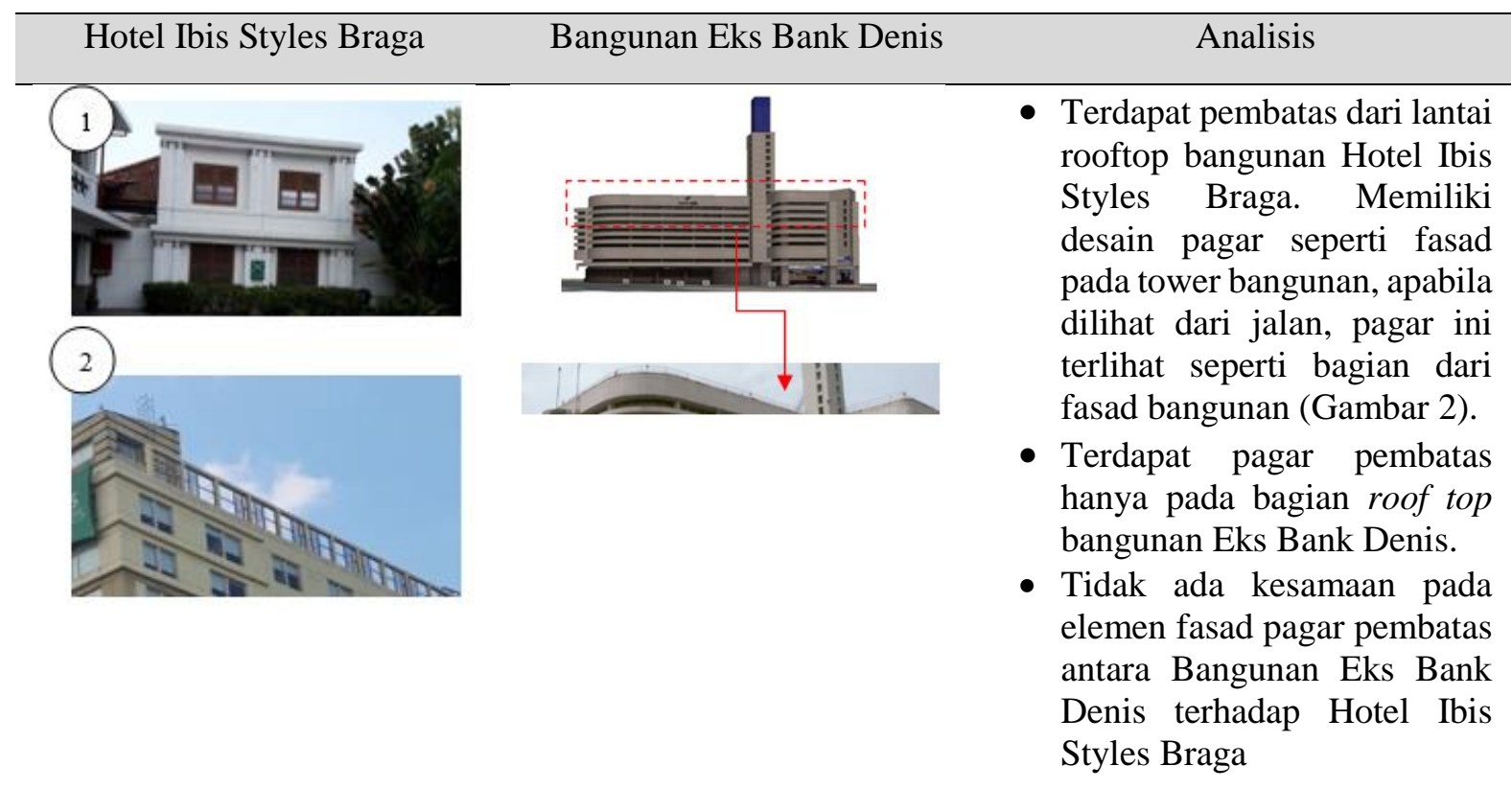

Sumber : Hasil Survei, 2019

\subsection{Atap dan Tingkat Loteng}

1. Analisis Kualitatif Atap dan Tingkat Loteng

Tabel 4. Analisa Kualitatif Perbandingan Elemen Fasad Atap dan Tingkat Loteng Bangunan Hotel Ibis Styles Braga Terhadap Bangunan Eks Bank Denis

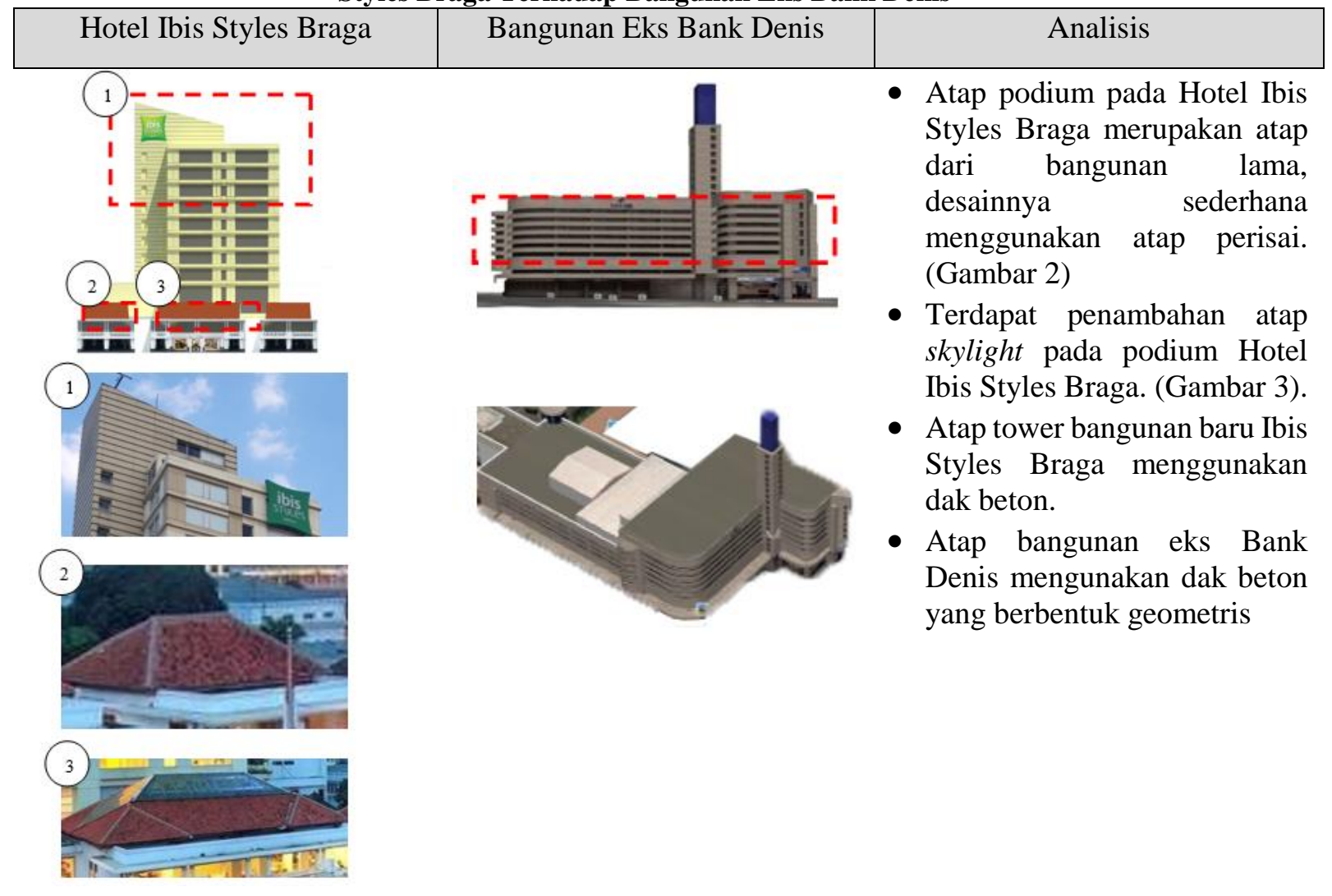

Sumber : Hasil Survei, 2019 
Reza, dkk.

\section{SIMPULAN}

Dari hasil analisis yang dilakukan pada penelitian dengan judul Kontekstualisme Elemen Fasad Hotel Ibis Styles Braga terhadap Fasad Bangunan eks Bank Denis Bandung dengan menggunakan metoda kualitatif dan kuantitatif dapat disimpulkan sebagai berikut:

1. Dalam proses desain bangunan Ibis Styles Braga mengadaptasi beberapa elemen fasad bangunan eks Bank Denis seperti bentuk bukaan dan irama pada pola fasadnya, namun dengan proporsi atau ukuran yang berbeda.

2. Berdasarkan analisa kualitatif, Hotel Ibis Styles Braga dan bangunan eks Bank Denis memiliki kesamaan desain fasad. Dilihat dari elemen-elemen pembentuk fasad yaitu gerbang dan pintu masuk, gang beratap (arcade), lantai dasar, jendela balkon dan logia, pagar pembatas atau railing, atap dan tingkat loteng yang secara kontinuitas visual memiliki beberapa kesamaan dalam bentuk dan irama bukaan fasad.

3. Berdasarkan analisa kuantitatif, secara ukuran \& proporsi elemen fasad Hotel Ibis Styles 'baru' memiliki perbandingan yang bebeda dengan bangunan eks Bank Denis.Ukuran proposi bangunan Hotel Ibis Styles baru cenderung memiliki ukuran yang lebih besar dibandingkan dengan proporsi elemen fasad pada eks Bank Denis dikarenakan faktor teknologi bahan pada saat ini telah mampu membuat material bahan yang berukuran besar.

4. Secara aspek kontekstual, Hotel Ibis Styles Braga cenderung memiliki pendekatan konsep selaras dengan bangunan eks Bank Denis.

Dengan demikian dapat disimpulkan bahwa tidak sepenuhnya bangunan Hotel Ibis Styles Braga mengadaptasi desain fasad eks Bank Denis, tetapi masih tetap memperhatikan aspek kontekstualisme pada perencanaan desain bangunanya.

\section{DAFTAR PUSTAKA}

[1] H. Kunto, Wajah Bandoeng Tempo Doeloe (Bandung in the past.). Bandung: Granesia, 1984.

[2] Undang-Undang Republik Indonesia Nomor 11 Tahun 2010 and C. Budaya, "Pk M . G Ha Um," Undang. Republik Indones. Nomor 11 Tahun 2010 Tentang Cagar Budaya, p. 54, 2010.

[3] P. Puspitasari and E. Marlina, "ARSITEKTUR KONTEKSTUAL PADA DESIGN BANGUNAN ( Kasus : Rancangan Gedung Medik Sentral RSUP Dr . Kariadi, Semarang ) CONTEXTUAL ARCHITECTURE CONCEPT ON BUILDING DESIGN ( Case : Design of General Hospital Dr . Kariadi Building, Semarang )," Pros. Semin. Intelekt. Muda \#1, no. April, pp. 14-20, 2019.

[4] B. C. Brolin, Architecture in Context. New York: Van Nostrand and Reinhold Company, 1980.

[5] I. Bentley, Responsive Environment. London: The Architectural Press, 1985.

[6] T. F. Bangunan, T. Ruang, and D. A. N. Arsitetkur, "M.. Suparno Sastra.2013, Inspirasi Fasade Rumah Tinggal. C.V Andi Offset, Yogyakarta. 48 Hal. 3," pp. 48-90, 2013.

[7] H. A. K. Eksklusif, "J*Frhmnozi," 2013.

[8] B. A. B. Iii, A. Metode, D. Penelitian, and D. Penelitian, "Pet Park," 2015.

[9] A. A. YUWONO, "Evaluasi Pasca Huni Bangunan Braga City Walk Bandung," Serat Rupa J. Des., vol. 1, no. 2, p. 222, 2018, doi: 10.28932/srjd.v1i2.451.

[10] R. M. Ichsan, "Analisis Benda Cagar Budaya sebagai Potensi Kawasan Wisata Perkotaan Kota Bogor," 2016, [Online]. Available: https://repository.ipb.ac.id/handle/123456789/85316. 